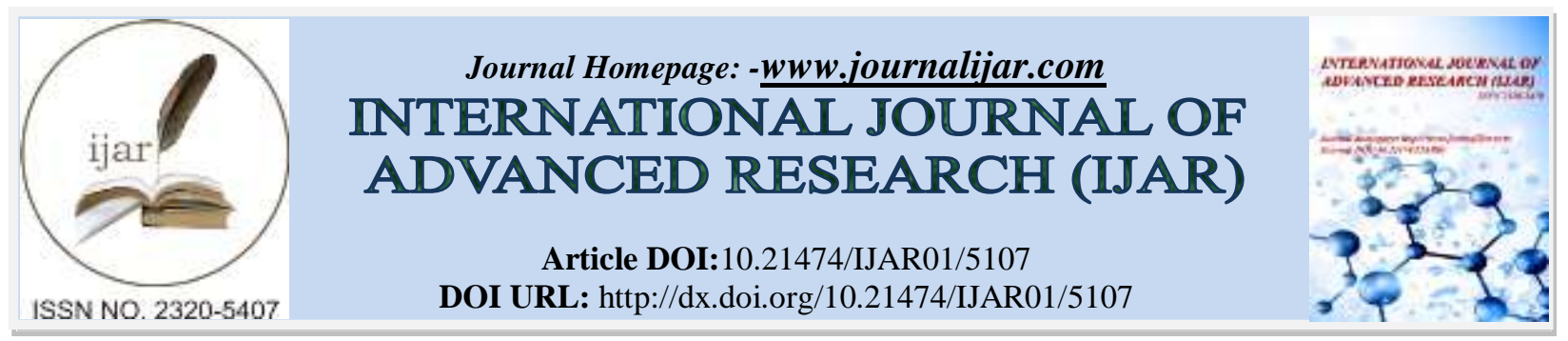

RESEARCH ARTICLE

\title{
DOCUMENTATION AND CARE OF CULTURAL HERITAGE OF BATTICALOA DISTRICT: ESTABLISHMENT OF CULTURAL HERITAGE UNIT AT THE LIBRARY OF EASTERN UNIVERSITY, SRI LANKA.
}

\author{
Gayathiri Navirathan. \\ Senior Assistant Librarian, Conservation and Preservation Unit and Periodicals Section Eastern University, Sri \\ Lanka.
}

\section{Manuscript Info}

Manuscript History

Received: 08 June 2017

Final Accepted: 10 July 2017

Published: August 2017

Keywords:-

Documentation, Care, Conservation,

Preservation, Cultural Heritage,

Historical Heritage.

\section{Abstract}

Documentation and care of priceless cultural heritage of mankind and preserving those collections of intellectual and cultural heritage become not only an academic commitment but also the moral responsibility of librarians. Library of Eastern University is the heart of the University and it plays an eminent role by providing resources and services not only for the staff and students but also for the community as well.

Therefore, this study focuses on cultural heritage of Batticaloa district and the objectives of the study were to explore the cultural and heritage materials or objects of Batticaloa district and documentation and care of them for present and future generations by conserve and preserving them and establishment of a Cultural Heritage Unit at the Library of Eastern University.

The data were collected through observation, focus group interview and objects survey. The collected data in the area of Batticaloa district comprises the rare objects or materials, antiquities, cultural and historical sites. Those collections are enriched with valuable and unique cultural, historical, religious and archeological value.

The Library of Eastern University consider about the documentation and care of immense cultural and historical heritage of the Eastern region especially Batticaloa district.

The Library has planned to maintain and sustains these unique, valuable and historical records of cultural heritage through the conservation and preservation practices the benefit of the both present and future. And for that, the Cultural Heritage Unit was established to exhibit those priceless collections and to document and care of them for the benefit of the community as whole.

Copy Right, IJAR, 2017,. All rights reserved.

\section{Introduction:-}

The library of Eastern University (EUSL Library) as the center of information resources facilitate the academic and research activities of the University teachers and students. The library of Eastern University is the major entity of providing precious collections of information resources and services and plays as unique to the University. The library already established a Conservation and Preservation unit which has valuable collections of rare or special 
collections. Apart from this, it has major responsibility to conserve and preserve the cultural heritage of the eastern region of Sri Lanka.

The Conservation and Preservation Unit in the EUSL library aims to acquire, preserve and provide access to rare and unique materials of cultural and historical value to smooth the progress of academic and research activities of all faculty staff and students and also aid access to the public if needed. By this the Library provides entity to document and care of cultural heritage of Batticaloa district. The uniqueness and rarity of the regional collections add more cultural, historical and traditional value of the materials.

And also, the long standing dream and ambition of the Library of Eastern University is to establish and maintain an exhibitory unit to conserve and preserve the valuable traditional and archeological materials to our Batticaloa district. For that, the study focuses to find out those cultural heritage materials and their historical and cultural value which should be documented and preserved for the continuation of the heritage to the present and future generation.

The Library of EUSL move steps into preserving large and diverse holdings of humanities for future generation and find ways to implement preventing conservation measures that are scientifically sound and sustainable. The Library also has the important collections of manuscripts which are to be preserved well for the generations. According to that the Library plays multi-dimensional and multi-faceted contributions to the Cultural Heritage of Eastern Sri Lanka.

The current study aims to conserve and preserve the precious cultural heritage materials by document and care of them and place in the Cultural Heritage Unit of the Library of Eastern University, Sri Lanka which is an exhibitory unit of Eastern Sri Lanka.

\section{Objectives:-}

1. To explore the cultural heritage objects available in Batticaloa district.

2. To compile background details of those materials and organizing them.

3. Documentation of them for researchers and academics who engaged in this field and for the use of future generation.

4. To establish a cultural heritage unit in the library of EUSL.

\section{Literature Review:-}

Chidac, R.A. (2013) reported that to preserving the old for younger generations, the most important is the condition in which these materials were stored and packed. In earliest past no one has cared of manuscripts or its content as government offices have never had the financial or administrative resources, nor the policies or procedures, to organize and manage their public records or registers. With time, they were deteriorated, infested with pests, insects and fungi, covered in dust and damp with humidity. Therefore, documentation and care of those priceless and most valuable assets would be the most essential responsibility of Librarians or custodians of Libraries, archives and Museums.

Jain, A. K. et.al (2013) emphasized that the huge treasure of knowledge is inherited as gift from ancestors in the form of manuscripts preserved down generations. The glorious past of culture lies in these manuscripts and those are basic historical evidences and have great research value. They constitute the memory of history, heritage and thought. The manuscripts which have survived for centuries have significance of antiquity. The materials of manuscript, the methods and techniques with which the leaf, bark or the paper was processed and the manners in which the inks were prepared also have great historical significance. The manuscripts need to be saved for their importance as methods of past society, culture and politics.

Sanchez-Carretero, Christina (2012) stated that, the heritage is a meta-cultural process in the sense of artifacts, buildings, landscapes, festivals or any other heritage elements are not by themselves heritage unless there is social value attached to them. Heritage is a peculiar type of cultural process because it implies the meta- cultural reflection about culture. Heritage implies the "adding value to culture".

Hanna M. Szczepanowska (2013) reported that, Conservation of cultural heritage is able to assist current professionals in understanding the multifaceted processes. The principle of practice for preservation and 
conservation remains the same and stems from the same base and it refers to consequences of interactions with the object, including reversibility whenever possible and minimal intervention.

For preventive conservation the general objective is to establish and maintain a stable environment to use nonreactive chemically inert materials in storage and on exhibition and to properly handle all artifacts. Pest management, housekeeping procedures and object handling are some of the top priority list for conservation. Just form the shape, inclusions, deposits of metal artifacts can be obtaining great information about their provenance, historical period, techniques of manufacture. Understanding how a metal object was made and finished determines which methods should be used for conservation treatment.

Jin, A.K.et.al (2013) stated that those manuscripts which have survived for centuries have significance of antiquity. Many of the manuscripts have been written by eminent personalities of their times or contain their thoughts. The material of the manuscripts, the methods and techniques with which the leaf, the bark or the paper was processed and the manners in which the inks were prepared also have great historical significance. The manuscripts need to be saved for their importance as records of past society, culture and politics.

Zaid,Y., Abioye,A and Olataise,O (2012) reported that efforts at preserving cultural heritage have gained new momentum throughout the world. The protection of cultural heritage is both economical and historical. A great number of people and organizations see cultural resources as critical to the nation's economic development.

The old knowledge was very important for the ancient era because in the past there were no any written and storage media available and only one media was present for storage and preserve the information or knowledge and tht is "human mind".

After the invention of writing media the scholars were store their knowledge in various media i.e. stone, wood, leather or in the form of manuscripts like papyrus, parchment, palm leaf, vellum and paper, which are the primary sources of the traditional knowledge in the present era. It is our responsibility to preserve them and to save for the next generation, because the ancient valuable resources are symbolizing our significance of cultural and tradition, which are describe the history of development of earlier civilization.

Navaneethakrishnan, S (2013) said that the preservation of cultural heritage has traditionally been dominated by the preservation of tangible forms of culture that represent communities' histories. In the last few years we have seen greater visibility and increased reforms of different initiatives in the field of preservation of cultural heritage carried out at local, national and international level. Impacts of these reforms on developing countries particularly on Sri Lanka have led paying an attention on the necessity of thinking according to the current trend.

Bordalo, R (2012) mentioned that the history has shown time and time again that (r) evolution is the only constant. Cultural heritage is all about our cultural identity, to know what we are and where we come from in order to understand how we are now. Cultural heritage is by definition past and unchangeable. Thus, if we can't adapt it to our society, perhaps we should try to adapt our society to it. At the end of the day it is only by embracing changes that we are going though that we can preserve cultural heritage and enable its present memory to be unaffected.

\section{Methodology:-}

To fulfill the objectives of this study, the methods will be used are observation, focus group interview and objects survey. The steps involve in methods were identifying the objects of cultural and historical value which are available in Batticaloa district, compiling background details of the cultural heritage collections, classifying the cultural materials, documentation of them and proper arrangements to store those valuable materials.

\section{Results and Discussion:-}

The rare collections or materials of cultural heritage were identified and compiled the background details of those collections of cultural heritage. The compiled rare objects collections were classified according to type, source of materials and the purpose or the usage of materials.

The types of rare collections found were the religious monuments, kitchen tools or utensils, vessels, furniture, farming tools, fishing tools, manuscripts, written documents, writing tools, storage utensils, ancient coins, rare trees, historic sites, religious monuments, measurement tools, video of unique cultural festivals and relics. The collected 
materials include tangible and intangible heritage of the area of Batticaloa District. The sources of collected materials are made of palm leaf, clay, bronze, stone, copper, ceramic, iron and wood.

Documentation of those collected rare cultural materials was done for the benefit of present literate and illiterate and also for the future generation as well.

While describing and cataloguing the objects the accurate and detailed description of objects should be provided as it facilitates to recognize and distinguish the cultural objects from other similar objects.

For the purpose of documentation internationally recognized standard for describing and cataloguing of rare or cultural materials were practiced. UNESCO (2007) mentioned an internationally recognized standard for describing and cataloguing is called object ID. It comprises object type, materials, technique, dimensions, inscriptions and markings, distinguishing features, title, subject, date and period of time, and maker. According to that standard the cultural objects were documented at the Library of Eastern University.

The details of documentation are as follows:

1. Object type: sculpture, vase, painting, manuscript, item of jewels...etc.

2. Materials: stone, ceramic, bronze or wood....etc

3. Techniques: carvings, cast, paint or print....etc.

4. Dimensions: height, weight, depth, diameter and weight.

5. Inscriptions and markings: makers mark or stamp, printed or inscribed text, signatures, assay marks and identification numbers.

6. Distinguishing features: damages, repairs, modifications, manufacturing defects...etc.

7. Title of the object.

8. Subject: For example if the object is an art work what it represents eg: pyramid, mother and child.

9. Date or period of the object.

10. Maker: Individual or group or company.

11. Short description: Colour, shape and place of the object made.

12. Additional points

Documentation of cultural materials is very crucial for the protection of those valuable and unique collections of cultural heritage. First step for the protection and care of those collections is the process of documentation. By the documentation everyone could to aware and understand the cultural collections well without direct observation which in turn provides an identity to find some forms of protection from natural and manmade hazards.

Effectual documentation could be attained by an extended process of collecting and recording data. The process of documentation is endless as knowledge and condition of those collections is changing through ages.

Documentation must be done for the valuable cultural collections because it is indispensable to understand the accurate perception of cultural property and therefore it's easy to find and preserve it for future generations.

On the other hand, the documentation allows us to record interferences on the objects, and to examining the cultural objects after the operation. In spite of all efforts on their protection, those cultural objects will deteriorate and decay. In this case, the documentation will be an evidence of what once existed.

From this research the existing cultural heritage materials available in different Divisional Secretariat divisions of Batticaloa district were identified and found the suitable methods to care of those valuable collections in the library. Those rare materials received from various people were placed in the established Cultural Heritage Unit at the Library of Eastern University, Sri Lanka.

The Cultural Heritage Unit was upheld to resemble the culture and history of Batticaloa district. And also it endows with valuable heritage resources which are provided to the researchers, academic professionals, students and for community as well. 
By this, safeguard the rare materials in Batticaloa district and prevention of materials which could be deteriorated by various factors. The established of Cultural Heritage Unit acts as a small museum and it definitely make the awareness of those cultural heritage materials among the public in near future.

\section{Conclusion:-}

The Library of Eastern University, Sri Lanka has consider the documentation and care of cultural heritage of Batticaloa district and established a cultural heritage unit or museum to protect and care the cultural objects of the area for make awareness and connect previous generation with present and future generations. By the establishment of Cultural Heritage Unit the Library of EUSL has broad scope of fulfilling the Preservation and Conservation of Eastern Provincial Cultural Heritage.

The broad diversity and expansive history of Batticaloa district shaped its cultural, religious and ethnic identity and it has inherited to the people in Eastern Sri Lanka with rich cultural and historical heritage which is worthy of being preserved and revived.

\section{References:-}

1. Bordalo, R (2012). e- Conservation: 23, March 2012. Portugal. Pp. 4.

2. Chidiac, R.A. (2013). The USEK Library: An Academic Library with a National Mission of Conserving the Heritage of Lebanon.IFLA WLIC 2013, Singapore.

3. Hanna M. S. (2013). Conservation of Cultural Heritage: Key Principles and Approaches. London-New York: Routledge. 2013, Pp. 317.

4. Jain, A. K. et.al (2013). Rare handwritten manuscript collection in Indic Languages at Scindia Oriental Research Institute (SORI), India. IFLA WLIC 2013, Singapore.

5. Navaneethakrishnan,S(2013). Preservation and Documentation of Intangible Cultural Heritage: the Strategic Role of the Library and Information Science Professionals in Sri Lanka. Journal of the University Librarians Association of Sri Lanka. 17(1). Pp. 58.

6. Sanchez-Carretero, C. (2012). Significance and social value of Cultural Heritage. Research Advances for the Conservation of Cultural Heritage. International Congress on Science and Technology for the Conservation of Cultural Heritage. Santiago de Compostela, Spain. 2012.

7. UNESCO (2007). Documentation of Artifacts' Collections. Cultural Heritage Protection Handbook. UNESCO 2007.

8. Zaid, Y., Abioye,A and Olataise, O (2012). Training in Cultural Heritage Preservation: The experience of Heritage Institutions in Nigeria. World Library and Information Congress: $78^{\text {th }}$ IFLA General Conference and Assembly. 2012. 